\title{
Prevention and treatment of venous thromboembolism during HRT: current perspectives
}

This article was published in the following Dove Press journal:

International Journal of General Medicine

I September 2014

Number of times this article has been viewed

\author{
Hannelore Rott \\ Coagulation Center Rhine-Ruhr, \\ Duisburg, Germany
}

Correspondence: Hannelore Rott Coagulation Center Rhine-Ruhr, Koenigstr 13,4705 I Duisburg, Germany Tel +492033483360

Fax +49 20334833636

Email hannelore.rott@gzrr.de
Abstract: Many large trials in the past 15 years have proven an increased risk of vascular complications in women using oral, mostly non-bioidentical, hormone therapy. The risk of vascular complications depends on the route of administration (oral versus transdermal), age, duration of administration, and type of hormones (bioidentical versus non-bioidentical). Acquired and/or hereditary thrombophilias (eg, factor V Leiden, prothrombin mutation G20210A, and others) lead to a further increase of risk for venous thromboembolism, stroke, or myocardial infarction. Therefore, bioidentical hormone therapy via the transdermal route seems to be the safest opportunity for hormone replacement therapy, although large trials for bioidentical hormone therapy are needed.

Keywords: hormone replacement therapy, stroke, myocardial infarction, thrombophilia, bioidentical hormone therapy

\section{Introduction}

Five major classes of human steroid hormones are known: estrogens, progestogens, androgens, mineralocorticoids, and glucocorticoids. The term "progestogen" refers to both the natural progesterone and synthetic compounds that have progestogenic activity similar to that of progesterone. The term "progestin" generally refers to synthetic progestogens. The term "progesterone" refers to the naturally occurring human molecule. ${ }^{1-3}$ Estrogens and progestogens are most commonly prescribed for the treatment of perimenopausal and menopausal symptoms such as hot flashes, night sweats, emotional lability, poor concentration, and sleep disturbance.

The endogenous estrogens found in humans include estradiol (E2), estriol (E3), estrone (E1), and their conjugates. The human ovary produces E2 and E1, whereas E3 is formed through $16 \alpha$-hydroxylation of E1 and E2. Before menopause, the predominant estrogen in circulation is E2, secreted by the ovaries. E1 is found in highest concentration after menopause and is converted from E2 and adrenal androstenedione in adipose tissue. E3 is short-acting and the least potent estrogen, and it is not converted, unlike E1, into E2. E2 has the highest affinity for both estrogen receptors (alpha and beta); E1 binds only to estrogen receptor alpha (which is located in breast cancer cells and the endometrium); and E3 binds weakly to both receptors.

Progesterone in a nonpregnant woman is secreted by the ovaries and adrenal glands. Progestogens are needed in hormone replacement therapy (HRT) to prevent endometrial hyperplasia or neoplasia when estrogen is administered. In "classic" HRT, mostly synthetic progestins, such as medroxyprogesteronacetate (MPA), are used. ${ }^{1}$ These synthetic progestins have different affinities for the progesterone receptor and 
they may also activate non-progesterone receptor steroid receptors in different tissues. ${ }^{4}$

Because of this, the most physiological way to apply HRT is to give bioidentical hormones transdermally without firstpass mechanism in the liver to avoid unphysiological changes and actions of the hormones, as described in the Oral nonbioidentical HRT and the risk of venous thromboembolism (VTE), stroke, and coronary heart disease (CHD) section.

\section{What types of sex hormones are used in HRT?}

One should keep in mind that there are many different types of sex hormones in use for HRT, including those that are partially synthetic, semisynthetic, derived from animal sources, or bioidentical (which means identical to the naturally occurring human hormones, bioidentical human hormones) (see Table 1).

The synthetic hormones, or those from animal sources, that are used in HRT do not contain the physiological amounts of E1, E2, and E3. The physiological proportion of E1, E2, and $\mathrm{E} 3$ in human blood is about $33 \% \mathrm{E} 1,45 \% \mathrm{E} 2,10 \% \mathrm{E} 3$,

Table I Types of sex hormones used in hormone replacement therapy

\begin{tabular}{l} 
Non-bioidentical estrogens, for example \\
Ethinyl E2 \\
Esterified estrogens \\
Conjugated equine estrogens \\
Dienestrol \\
Mestranol \\
Bioidentical estrogens, for example \\
Estrone sulfate \\
Estropipate \\
Estradiol \\
Estriol \\
Progestins (non-bioidentical), for example \\
Medroxyprogesterone acetate \\
Norethindrone (acetate) \\
Norgestrel \\
Levonorgestrel \\
Desogestrel \\
Norgestimate \\
Megestrol acetate \\
Drospirenone \\
Etonogestrel \\
Medrogestone \\
Dydrogesterone \\
Progesterone (bioidentical) \\
Progesterone \\
Other \\
Tibolone \\
\hline Note: Dafrom Moskovz.
\end{tabular}

Note: Data from Moskovitz. ${ }^{3}$ Abbreviation: E2, estradiol. and about $10 \%$ metabolites of E1 and E2. ${ }^{5}$ 2 2 is the most potent human estrogen. The distribution of estrogens in non-bioidentical estrogens differs significantly from human estrogens; this is especially true for conjugated equine estrogens (CEE) (see Figure 1).

Progestins are synthetic progestogens, which are mostly used in HRT. The only bioidentical progestogen is progesterone (see Table 1).

Both estrogens and progestins/progesterone can be used orally, transdermally, intranasally, or intramuscularly.

\section{Oral non-bioidentical HRT and the risk of venous thromboembolism (VTE), stroke, and coronary heart disease (CHD)}

Table 2 shows the absolute risk of VTE in women with and without HRT.

Many large trials in the past 15 years, for example, the Women's Health Initiative (WHI) trial in $2002^{6,7}$ and the Women's International Study of long Duration Oestrogen after Menopause (WISDOM) trial, ${ }^{8}$ showed a marked increase in the risk of VTE in women using oral non-bioidentical HRT. Of note, most of the women in these trials used oral CEE + MPA.

In the WHI trial, the risk of VTE in HRT patients was double that of patients in the placebo group, ${ }^{6}$ in the Heart and Estrogen/progestin Replacement Study (HERS), the VTE risk was nearly threefold; ${ }^{9}$ and, in the ESTHER study, the risk was fourfold ${ }^{10}$ (see Table 3). VTE risk is much higher in women taking CEE than in women taking oral esterified estrogens. ${ }^{11}$

The risk of VTE while taking CEE + MPA increases with age. Compared with women between the ages of 50-59 years who were taking placebo, the risk associated with HRT was higher with age: hazard ratio (HR) of 4.28 for women aged 60-69 years and 7.46 for women aged 70-79 years. Compared with women who were of normal weight and taking placebo, the risk associated with taking estrogen + progestin was increased among overweight (HR 3.8) and obese women (HR5.61), respectively. ${ }^{12}$ The VTE risk in oral HRT users is highest in the first year of use, ${ }^{13,14}$ then declines, but remains on a higher level compared to nonusers. There is no elevated risk for past users of HRT after 6 weeks of stopping HRT. ${ }^{15}$

The risk of VTE recurrence is lower in women who developed VTE on estrogen replacement and then stopped the HRT. This shows that, in most women with VTE on HRT, the HRT was the main risk factor. ${ }^{16}$ 


\section{A Free human estrogens}

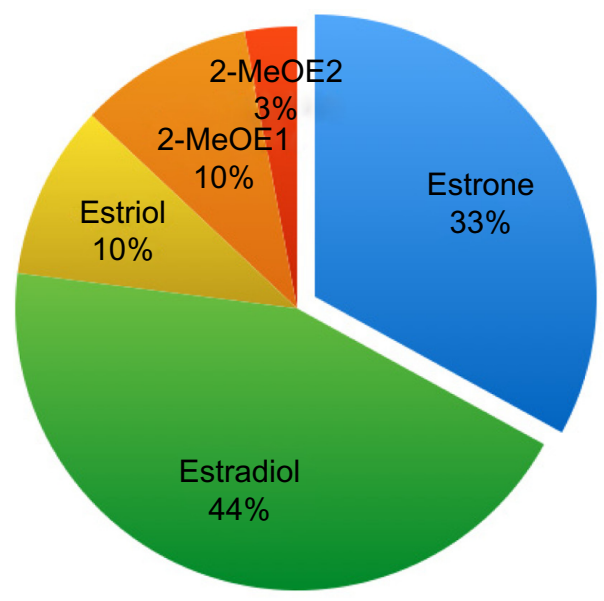

B Conjugated equine estrogens

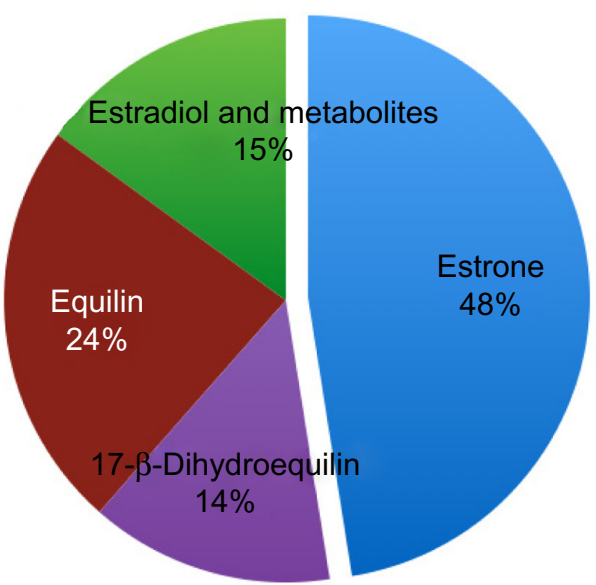

Figure I Distribution of estrogens in women and horses.

Notes: (A) Normal estrogen distribution in nonpregnant women. (B) Distribution of estrogens in pregnant horses.

Abbreviations: 2-MeOEI, 2-methoxyestrone; 2-MeOE2, 2-methoxyestradiol.

The use of oral non-bioidentical HRT is associated with an overall $29 \%$ increase in the risk of ischemic stroke. The severity of stroke (poor functional outcome, death, disability, or dependency) increased with oral non-bioidentical HRT, with a nonsignificant increase of fatal stroke. ${ }^{17}$ Tibolone, an oral synthetic steroid hormone similar to norethisterone and with estrogenic, progestogenic, and androgenic effects, also leads to an excess risk of stroke (odds ratio [OR] 2.18). ${ }^{18}$

Oral CEE in combination with MPA was associated with an HR of 1.24 for CHD and not a protection against cardiac diseases, as was initially expected. ${ }^{19}$ In postmenopausal women who had survived a myocardial infarction, the oral use of $2 \mathrm{mg}$ E2 valerate did not reduce the overall risk for further cardiac events. ${ }^{20}$ Women, who initiated hormone therapy (CEE) after hysterectomy closer to menopause tended to have reduced CHD risk compared with the increase in CHD risk among women more distant from menopause, but this trend test did not meet our criterion for statistical significance. The

Table 2 Absolute risk of VTE in peri- and postmenopausal women with and without HRT

\begin{tabular}{lll}
\hline Age & $\begin{array}{l}\text { Absolute } \\
\text { risk of VTE } \\
\text { without HRT }\end{array}$ & $\begin{array}{l}\text { Absolute risk of VTE } \\
\text { with HRT (oral } \\
\text { estrogen + progestin) }\end{array}$ \\
\hline $50-59$ years & 0.8 & 2.27 \\
$60-69$ years & 1.9 & 4.28 \\
$70-79$ years & 2.7 & 7.46 \\
\hline
\end{tabular}

Notes: Annualized rate/I,000 person years. Data from Chushmann et al. ${ }^{12}$

Abbreviations: HRT, hormone replacement therapy; VTE, venous thromboembolism. risk for stroke was increased in this study regardless of years since menopause. ${ }^{21}$ In a group of women aged $45-58$ years who were treated with either $2 \mathrm{mg}$ oral E2 + norethisterone acetate, or in cases who had undergone hysterectomy with oral E2 alone, there was a significantly reduced risk of mortality, heart failure, and myocardial infarction. ${ }^{22}$

Given the above results, the type of oral HRT, for example CEE + MPA versus E2 (which is a natural hormone) + progestogen of different types might be very important in terms of the risk of vascular complications. Of note, HRT with oral CEE + MPA did not have clinically meaningful effects on health-related quality of life. ${ }^{23}$

The main reason for the increased risk for vascular complications in oral HRT is primarily the estrogen component; the progestin only modifies this risk, as is already known to be the case with oral contraception. ${ }^{24}$ The amount of coagulation activation also seems to be dependent on the estrogen dosage used. ${ }^{25}$

High endogenous levels of sex hormones of E2 and testosterone in the general population are not associated with increased risk of VTE. ${ }^{26}$

Only one study of testosterone application in women and cardiovascular disease exists, and no increased risk of cardiovascular disease could be found in women prescribed testosterone tablets, injections, or implants. ${ }^{27}$

\section{Transdermal HRT and the risk of VTE}

Sex hormones can be given easily via a transdermal route as a patch or gel/cream. 
Table 3 Risk for VTE, stroke, and CHD in women using oral, non-bioidentical hormone replacement therapy

\begin{tabular}{|c|c|c|c|c|}
\hline Risks & HERS 9 & WHI trial ${ }^{6,7}$ & WISDOM study ${ }^{8}$ & ESTHER study'10 \\
\hline VTE & RH 2.89 & HR 2.13 & HR 7.36 & OR 4.2 \\
\hline Myocardial infarction or death from $\mathrm{CHD}$ & RH 0.99 & HR I.29 & Significant increase & Not detected \\
\hline Stroke or cerebral vascular accident & Not detected & HR I.4I & No increase & Not detected \\
\hline
\end{tabular}

Note: Data from Rossouw et al, ${ }^{6}$ Anderson et al, ${ }^{7}$ Vickers et al, ${ }^{8}$ Hulley et al, ${ }^{9}$ and Canonico et al. ${ }^{10}$

Abbreviations: CHD, coronary heart disease; HERS, Heart and Estrogen/progestin Replacement Study; HR, hazard ratio; OR, odds ratio; RH, relative hazard; VTE, venous thromboembolism; WHI, Women's Health Initiative; WISDOM, Women's International Study of long Duration Oestrogen after Menopause.

Both estrogens and progestogens have very good bioavailability when given transdermally. Another advantage of giving estrogens transdermally is the avoidance of the so-called first-pass mechanism in the liver. In the first-pass mechanism, which occurs only when steroid hormones are given orally, the structure of the hormones can change due to metabolizing effects, leading to formation of unphysiological molecules and activation of receptors of other steroid hormones. One possible consequence, among others, is a hypercoagulable state and a sometimes greatly reduced concentration of the drug, with the necessity of much higher doses needed orally in comparison to transdermal administration. With oral HRT, coagulation activation occurs (eg, higher levels of coagulation factor VII, greater thrombin generation peak levels, higher endogenous thrombin potential, higher level of prothrombin fragment 1.2$)^{28}$ and anticoagulants decrease (eg, antithrombin, protein $\mathrm{C}$, protein $\mathrm{S}$, tPA); ${ }^{29,30-32}$ an acquired APC resistance phenotype can also occur. ${ }^{33}$ Thrombin generation is significantly increased in women who use HRT orally (Table 4). This may be mediated by the first-pass metabolism of E1, the main metabolite of E2, because plasma E1 levels are higher in women taking oral estrogen..$^{34}$ The level of high-density lipoprotein cholesterol can increase ${ }^{35}$ and the level of lipoprotein(a) decrease ${ }^{36}$ while patients are on oral HRT, but this has obviously no clinical protective effect against arterial complications, as shown in the Oral non-bioidentical HRT and the risk of venous thromboembolism (VTE), stroke, and coronary heart disease (CHD) section.

In a multicenter case-control study in postmenopausal women in France, oral use of estrogen (E2, mean dose $1.5 \mathrm{mg}$ )

Table 4 Changes in coagulation and metabolic parameters in users of oral versus transdermal hormone replacement therapy (HRT)

\begin{tabular}{lll}
\hline Coagulation parameter & Oral HRT & Transdermal HRT \\
\hline D-dimer & Increase & No change \\
Protein S & Decrease & No change \\
Antithrombin & Decrease & No change \\
APC ratio & Decrease & No change \\
Thrombin generation & Increase & No change \\
Factor VII & Increase & No change \\
\hline
\end{tabular}

Abbreviation: APC, activated protein C. was associated with a fourfold risk of VTE, especially when combined with norpregnane derivatives, whereas E2 via the transdermal route showed an OR of 0.9 for VTE. ${ }^{10,37}$

Roach et al showed that non-oral HRT did not increase the risk of VTE, but oral HRT did, by fourfold. ${ }^{38}$ Another nested case-control study came to the same conclusion, with a relative risk of VTE of about 1.5 for oral estrogen use and no increase of VTE risk for transdermal use of estrogen. ${ }^{39}$ The same was true in another study from 2011 involving around 54,000 women and comparing transdermal with oral estrogen use. The incidence ratio for VTE in transdermal users was $0.72 .{ }^{40}$

Intranasal application of E2 + norethisterone is also not associated with an activation of the coagulation system. ${ }^{41}$

\section{Thrombophilia and HRT}

For the absolute risk of VTE in women over 49 years, see Table 5. ${ }^{12}$

The condition of thrombophilia can be hereditary (eg, factor V Leiden (FVL) mutation; prothrombin mutation G20210A [PTM]; deficiencies of antithrombin, protein C, or protein $\mathrm{S}$; elevated lipoprotein[a]; non-O blood group ${ }^{42}$ ); acquired (obesity, smoking, varicosis, chronic inflammatory bowel disease, rheumatic diseases, intake of corticosteroids, antiphospholipid syndrome, hyperhomocysteinemia, elevated factor VIII levels, surgery, cast, etc) $;{ }^{43}$ or, often, a combination of both.

In a case-control study in women aged 45-64 years, the relative risk of idiopathic VTE in HRT users showed a significant association with APC resistance (OR 4.06), low antithrombin levels (OR 3.33), low protein C levels (OR 2.93), or high D-dimer levels (OR 3.84). D-dimer levels rose in patients on oral HRT, ${ }^{44}$ but transdermal HRT had no effect in this regard. ${ }^{30}$ Carriers of APC resistance/FVL who used oral HRT had a 13-fold increase of VTE risk. ${ }^{45}$ Two other studies found similar results, with an OR of about 14 for women with FVL + oral HRT compared to women assigned to placebo. ${ }^{46,47}$

In another study in postmenopausal women with idiopathic VTE, the combination of either FVL or PTM and oral estrogen was associated with a 25 -fold increased risk of VTE compared with non-users without mutation. 
FVL or PTM alone without oral estrogen use showed ORs of 3.4 and 4.8, respectively for VTE; however, the risk for women with prothrombotic mutation using transdermal estrogen was similar to that of women with a prothrombotic mutation who were not using estrogen..$^{48}$

For the other known hereditary thrombophilias, such as deficiencies of antithrombin, protein $\mathrm{C}$, and protein $\mathrm{S}$ or elevation of lipoprotein(a), no data exist for the VTE risk in HRT users; the same is true for the acquired thrombophilic disorder antiphospholipid syndrome. This may be due to the rarity of these conditions (see Table 5).

Combined hereditary risk factors, eg, the combination of non-O blood group and either FVL or PTM, further increases the risk of VTE and myocardial infarction. ${ }^{49}$

In a study from 2001, in which postmenopausal women received mainly esterified oral estrogens, the risk of nonfatal myocardial infarction was increased eleven-fold in women with PTM compared with women without HRT and the wild-type genotype..$^{50}$

There are no further data regarding the roles of specific thrombophilias and HRT on the risk of CHD or stroke.

\section{Bioidentical HRT (BHR)}

The finding that the CCE + MPA arm, in particular, of the WHI study showed more risks than benefits for the patients led to a dramatically changed prescribing practice of HRT all over the world. ${ }^{51}$ In USA, prescription of CEE + MPA has decreased by $63 \%$ between 2002 and now. A substantial number of patients expressed a loss of trust in information about HRT and in their physicians after publication of the WHI Trial. Furthermore, many women desire a "natural" alternative medication for treating menopausal symptoms. BHR may be one such alternative.

Endocrinologists define bioidentical hormones as compounds that have exactly the same chemical and molecular structure as hormones that are produced in the human body. This is only true for a few estrogens and for the only natural progestogen (progesterone) (see Table 1). The bioidentical hormones are usually derived from plant sources. Progesterone is available as oral micronized progesterone in oil or for vaginal use as gel or capsules. The micronized form of progesterone improves absorption of oral progesterone. The most common combinations for BHR include endogenous estrogen (mostly E2, E1, E3) and progesterone, preferably transdermally. Sometimes other ingredients, such as testosterone, are added. In Europe in particular, several bioidentical formulations for transdermal application are approved, for example E2 (oral 1-2 mg, or as a patch [25-100 $\mu \mathrm{g} / 24 \mathrm{~h}])$ and E3 $(0.5-2 \mathrm{mg})$ for oral and transdermal or vaginal use. Natural micronized progesterone (100 $\mathrm{mg}$ capsule for oral or vaginal use) is also approved in most countries. Some small studies have shown favorable effects of BHR on myocardial ischemia and cardiovascular biomarkers. ${ }^{52-54}$

A recently published study showed a higher, doubled risk of VTE and possibly myocardial infarction in users of oral CEE compared to oral E2. ${ }^{55}$ Another study showed a 2.5 -fold risk for VTE in users of CEE, and the risk was much higher

Table 5 Thrombophilias and risk of VTE

\begin{tabular}{|c|c|c|}
\hline Thrombophilia & VTE risk without HRT (OR) & VTE risk with HRT (OR) \\
\hline Factor $\vee$ Leiden mutation, heterozygous & 5 & $13-25$ \\
\hline Factor V Leiden mutation, homozygous & 10 & $\begin{array}{l}\text { Higher than for heterozygous; } \\
\text { thus far not sufficiently studied }\end{array}$ \\
\hline Prothrombin mutation G202I0A, heterozygous & 3 & $13-25$ \\
\hline Prothrombin mutation G202I0A, homozygous & No data & $\begin{array}{l}\text { Higher than for heterozygous; } \\
\text { thus far not sufficiently studied }\end{array}$ \\
\hline $\begin{array}{l}\text { Prothrombin G202I0A mutation, heterozygous + } \\
\text { factor V Leiden mutation, heterozygous }\end{array}$ & $4-15$ & No data \\
\hline Congenital Protein S deficiency & $5-11$ & No data \\
\hline Congenital Protein $\mathrm{C}$ deficiency & $3-15$ & No data \\
\hline Congenital antithrombin deficiency & $\begin{array}{l}\text { 4-50, depending on type of } \\
\text { AT deficiency (type I or II) }\end{array}$ & No data \\
\hline Factor VIII elevation & $5-8$ & No data \\
\hline $\begin{array}{l}\text { Antiphospholipid antibodies (lupus anticoagulants, } \\
\text { anti-cardiolipin antibodies, anti- } \beta 2 \text {-glycoprotein I antibodies) }\end{array}$ & $\begin{array}{l}2-16 \text {, depending on antibody } \\
\text { titer or combination thereof }\end{array}$ & No data \\
\hline Hyperhomocysteinemia & $\begin{array}{l}\text { Risk rises by } 1.3 \text { for each } \\
\text { increase of } 5 \mu \mathrm{mol}\end{array}$ & No data \\
\hline Lipoprotein(a) $>30 \mathrm{mg} / \mathrm{dL}$ & 1.8 & No data \\
\hline MTHFR polymorphisms & Not elevated & No data \\
\hline
\end{tabular}

Abbreviations: HRT, hormone replacement therapy; OR, odds ratio; VTE, venous thromboembolism; MTHFR, methylenetetrahydrofolate reductase. 
for women with hereditary thrombophilia (OR 9.1). In this study, the use of esterified estrogen was not associated with a higher risk for VTE without thrombophilia. ${ }^{56}$

BHR has also been demonstrated to cure typical menopausal symptoms ${ }^{57-59}$ while lowering lipid levels. ${ }^{60}$

BHR, usually applied transdermally, seems to be a more physiological and safer alternative to classic HRT (eg, CEE + MPA), but large clinical studies are needed to confirm this.

\section{Conclusion}

Many different types of HRT exist (synthetic versus bioidentical, oral versus transdermal, etc), so the results, benefits, and risks of a particular type of HRT should not be assumed of other types of HRT.

The highest risk for vascular complications is associated with oral, non-bioidentical HRT, especially with oral CEE + MPA or with oral estrogens + synthetic progestins. Oral HRT shows an increased risk of vascular complications, while transdermal applications do not. Women with hereditary and/ or acquired risk factors or a history of vascular complications should use transdermal and not oral HRT.

Transdermal BHR is possibly the best choice for any woman wishing to use HRT, but further studies on this option are needed.

\section{Acknowledgment}

I would like to thank my colleague Dr Guether Kapper for the creation of Figure 1.

\section{Disclosure}

The author reports no conflicts of interest in this work.

\section{References}

1. Files JA, Ko MG, Pruthi S. Bioidentical hormone therapy. Mayo Clin Proc. 2011;86(7):673-680.

2. Conaway E. Bioidentical hormones: an evidence-based review for primary care providers. J Am Osteopath Assoc. 2011;111(3):153-164.

3. Moskowitz D. A comprehensive review of the safety and efficacy of bioidentical hormones for the management of menopause and related health risks. Altern Med Rev. 2006;11(3):208-223.

4. Holtorf K. The bioidentical hormone debate: are bioidentical hormones (estradiol, estriol, and progesterone) safer or more efficacious than commonly used synthetic versions in hormone replacement therapy? Postgrad Med. 2009;121(1):73-85.

5. Xu X, Roman JM, Issaq HJ, Keefer LK, Veenstra TD, Ziegler RG. Quantitative measurement of endogenous estrogens and estrogen metabolites in human serum by liquid chromatography-tandem mass spectrometry. Anal Chem. 2007;79(20):7813-7821.

6. Rossouw JE, Anderson GL, Prentice RL, et al; Writing Group for the Women's Health Initiative Investigators. Risks and benefits of estrogen plus progestin in healthy postmenopausal women: principal results from the Women's Health Initiative randomized controlled trial. JAMA. 2002;288(3):321-333.
7. Anderson GL, Limacher M, Assaf AR, et al; Women's Health Initiative Steering Committee. Effects of conjugated equine estrogen in postmenopausal women with hysterectomy: the Women's Health Initiative randomized controlled trial. JAMA. 2004;291(14): 1701-1712.

8. Vickers MR, MacLennan AH, Lawton B, et al; WISDOM group. Main morbidities recorded in the women's international study of long duration oestrogen after menopause (WISDOM): a randomised controlled trial of hormone replacement therapy in postmenopausal women. $B M J$. 2007;335(7613):239.

9. Hulley S, Grady D, Bush T, et al. Randomized trial of estrogen plus progestin for secondary prevention of coronary heart disease in postmenopausal women. Heart and Estrogen/progestin Replacement Study (HERS) Research Group. JAMA. 1998;280(7):605-613.

10. Canonico M, Oger E, Plu-Bureau G, et al; Estrogen and Thromboembolism Risk (ESTHER) Study Group. Hormone therapy and venous thromboembolism among postmenopausal women: impact of the route of estrogen administration and progestogens: the ESTHER study. Circulation. 2007;115(7):840-845.

11. Smith NL, Heckbert SR, Lemaitre RN, et al. Esterified estrogens and conjugated equine estrogens and the risk of venous thrombosis. JAMA. 2004;292(13):1581-1587.

12. Cushman M, Kuller LH, Prentice R, et al; Women's Health Initiative Investigators. Estrogen plus progestin and risk of venous thrombosis. JAMA. 2004;292(13):1573-1580.

13. Pérez Gutthann S, García Rodríguez LA, Castellsague J, Duque Oliart A. Hormone replacement therapy and risk of venous thromboembolism: population based case-control study. BMJ. 1997;314(7083):796-800.

14. Høibraaten E, Qvigstad E, Arnesen H, Larsen S, Wickstrøm E, Sandset PM. Increased risk of recurrent venous thromboembolism during hormone replacement therapy - results of the randomized, double-blind, placebo-controlled estrogen in venous thromboembolism trial (EVTET). Thromb Haemost. 2000;84(6):961-967.

15. Canonico M, Fournier A, Carcaillon L, et al. Postmenopausal hormone therapy and risk of idiopathic venous thromboembolism: results from the E3N cohort study. Arterioscler Thromb Vasc Biol. 2010;30(2):340-345.

16. Eischer L, Eichinger S, Kyrle PA. The risk of recurrence in women with venous thromboembolism while using estrogens: a prospective cohort study. J Thromb Haemost. 2014;12(5):635-640.

17. Bath PM, Gray LJ. Association between hormone replacement therapy and subsequent stroke: a meta-analysis. BMJ. 2005;330(7487):342.

18. Formoso G, Perrone E, Maltoni S, et al. Short and long term effects of tibolone in postmenopausal women. Cochrane Database Syst Rev. 2012;2:CD008536.

19. Manson JE, Hsia J, Johnson KC, et al; Women's Health Initiative Investigators. Estrogen plus progestin and the risk of coronary heart disease. N Engl J Med. 2003;349(6):523-534.

20. Cherry N, Gilmour K, Hannaford P, et al; ESPRIT team. Oestrogen therapy for prevention of reinfarction in postmenopausal women: a randomised placebo controlled trial. Lancet. 2002;360(9350):2001-2008.

21. Rossouw JE, Prentice RL, Manson JE, et al. Postmenopausal hormone therapy and risk of cardiovascular disease by age and years since menopause. JAMA. 2007;297(13):1465-1477.

22. Schierbeck LL, Rejnmark L, Tofteng CL, et al. Effect of hormone replacement therapy on cardiovascular events in recently postmenopausal women: randomised trial. BMJ. 2012;345:e6409.

23. Hays J, Ockene JK, Brunner RL, et al; Women's Health Initiative Investigators. Effects of estrogen plus progestin on health-related quality of life. N Engl J Med. 2003;348(19):1839-1854.

24. Lidegaard Ø, Nielsen LH, Skovlund CW, Skjeldestad FE, Løkkegaard E. Risk of venous thromboembolism from use of oral contraceptives containing different progestogens and oestrogen doses: Danish cohort study, 2001-2009. BMJ. 2011;343:d6423.

25. Koh KK, Shin MS, Sakuma I, et al. Effects of conventional or lower doses of hormone replacement therapy in postmenopausal women. Arterioscler Thromb Vasc Biol. 2004;24(8):1516-1521. 
26. Holmegard HN, Nordestgaard BG, Schnohr P, Tybjaerg-Hansen A, Benn $M$. Endogenous sex hormones and risk of venous thromboembolism in women and men. J Thromb Haemost. 2014;12(3):297-305.

27. van Staa TP, Sprafka JM. Study of adverse outcomes in women using testosterone therapy. Maturitas. 2009;62(1):76-80.

28. Blondon M, van Hylckama Vlieg A, Wiggins KL, et al. Differential associations of oral estradiol and conjugated equine estrogen with hemostatic biomarkers. J Thromb Haemost. 2014;12(6):879-886.

29. van Baal WM, Emeis JJ, van der Mooren MJ, Kessel H, Kenemans P, Stehouwer CD. Impaired procoagulant-anticoagulant balance during hormone replacement therapy? A randomised, placebo-controlled 12-week study. Thromb Haemost. 2000;83(1):29-34.

30. Post MS, Christella M, Thomassen LG, et al. Effect of oral and transdermal estrogen replacement therapy on hemostatic variables associated with venous thrombosis: a randomized, placebo-controlled study in postmenopausal women. Arterioscler Thromb Vasc Biol. 2003;23(6):1116-1121.

31. Scarabin PY, Alhenc-Gelas M, Plu-Bureau G, Taisne P, Agher R, Aiach M. Effects of oral and transdermal estrogen/progesterone regimens on blood coagulation and fibrinolysis in postmenopausal women: a randomized controlled trial. Arterioscler Thromb Vasc Biol. 1997;17(11):3071-3078.

32. Teede HJ, McGrath BP, Smolich JJ, et al. Postmenopausal hormone replacement therapy increases coagulation activity and fibrinolysis. Arterioscler Thromb Vasc Biol. 2000;20(5):1404-1409.

33. Oger E, Alhenc-Gelas M, Lacut K, et al; SARAH Investigators. Differential effects of oral and transdermal estrogen/progesterone regimens on sensitivity to activated protein $\mathrm{C}$ among postmenopausal women: a randomized trial. Arterioscler Thromb Vasc Biol. 2003;23(9):1671-1676.

34. Bagot CN, Marsh MS, Whitehead M, et al. The effect of estrone on thrombin generation may explain the different thrombotic risk between oral and transdermal hormone replacement therapy. JThromb Haemost. 2010;8(8):1736-1744.

35. [No authors listed]. Effects of estrogen or estrogen/progestin regimens on heart disease risk factors in postmenopausal women. The Postmenopausal Estrogen/Progestin Interventions (PEPI) Trial. The Writing Group for the PEPI Trial. JAMA. 1995;273(3):199-208.

36. Soma MR, Osnago-Gadda I, Paoletti R, et al. The lowering of lipoprotein[a] induced by estrogen plus progesterone replacement therapy in postmenopausal women. Arch Intern Med. 1993;153(12):1462-1468.

37. Scarabin PY, Oger E, Plu-Bureau G; EStrogen and THromboEmbolism Risk Study Group. Differential association of oral and transdermal oestrogen-replacement therapy with venous thromboembolism risk. Lancet. 2003;362(9382):428-432.

38. Roach RE, Lijfering WM, HelmerhorstFM, Cannegieter SC, RosendaalFR, van Hylckama Vlieg A. The risk of venous thrombosis in women over 50 years old using oral contraception or postmenopausal hormone therapy. J Thromb Haemost. 2013;11(1):124-131.

39. Renoux C, Dell'Aniello S, Suissa S. Hormone replacement therapy and the risk of venous thromboembolism: a population-based study. J Thromb Haemost. 2010;8(5):979-986.

40. Laliberté F, Dea K, Duh MS, Kahler KH, Rolli M, Lefebvre P. Does the route of administration for estrogen hormone therapy impact the risk of venous thromboembolism? Estradiol transdermal system versus oral estrogen-only hormone therapy. Menopause. 2011;18(10):1052-1059.

41. Hemelaar M, Rosing J, Kenemans P, Thomassen MC, Braat DD, van der Mooren MJ. Less effect of intranasal than oral hormone therapy on factors associated with venous thrombosis risk in healthy postmenopausal women. Arterioscler Thromb Vasc Biol. 2006;26(7):1660-1666.

42. Guimarães DA, dos Santos MS, Gomes KB, et al. Interaction between oral estrogen plus progestogen therapy and $\mathrm{ABO}$ blood groups on coagulation activation in postmenopausal women. Menopause. 2012;19(3):339-345.

43. Bergendal A, Bremme K, Hedenmalm K, et al. Risk factors for venous thromboembolism in pre-and postmenopausal women. Thromb Res. 2012;130(4):596-601.
44. Sumino H, Ichikawa S, Sawada Y, et al. Effects of hormone replacement therapy on blood coagulation and fibrinolysis in hypertensive and normotensive postmenopausal women. Thromb Res. 2005; 115(5):359-366.

45. Lowe G, Woodward M, Vessey M, Rumley A, Gough P, Daly E. Thrombotic variables and risk of idiopathic venous thromboembolism in women aged 45-64 years. Relationships to hormone replacement therapy. Thromb Haemost. 2000;83(4):530-535.

46. Herrington DM, Vittinghoff E, Howard TD, et al. Factor V Leiden, hormone replacement therapy, and risk of venous thromboembolic events in women with coronary disease. Arterioscler Thromb Vasc Biol. 2002;22(6):1012-1017.

47. Wu O, Robertson L, Langhorne $\mathrm{P}$, et al. Oral contraceptives, hormone replacement therapy, thrombophilias and risk of venous thromboembolism: a systematic review. The Thrombosis: Risk and Economic Assessment of Thrombophilia Screening (TREATS) Study. Thromb Haemost. 2005;94(1):17-25.

48. Straczek C, Oger E, Yon de Jonage-Canonico MB, et al; Estrogen and Thromboembolism Risk (ESTHER) Study Group. Prothrombotic mutations, hormone therapy, and venous thromboembolism among postmenopausal women: impact of the route of estrogen administration. Circulation. 2005;112(22):3495-3500.

49. Sode BF, Allin KH, Dahl M, Gyntelberg F, Nordestgaard BG. Risk of venous thromboembolism and myocardial infarction associated with factor V Leiden and prothrombin mutations and blood type. CMAJ. 2013;185(5):E229-E237.

50. Psaty BM, Smith NL, Lemaitre RN, et al. Hormone replacement therapy, prothrombotic mutations, and the risk of incident nonfatal myocardial infarction in postmenopausal women. JAMA. 2001;285(7):906-913.

51. Hersh AL, Stefanick ML, Stafford RS. National use of postmenopausal hormone therapy: annual trends and response to recent evidence. JAMA. 2004;291(1):47-53.

52. Stephenson K, Neuenschwander PF, Kurdowska AK. The effects of compounded bioidentical transdermal hormone therapy on hemostatic, inflammatory, immune factors; cardiovascular biomarkers; quality-oflife measures; and health outcomes in perimenopausal and postmenopausal women. Int J Pharm Compd. 2013;17(1):74-85.

53. Rosano GM, Webb CM, Chierchia S, et al. Natural progesterone, but not medroxyprogesterone acetate, enhances the beneficial effect of estrogen on exercise-induced myocardial ischemia in postmenopausal women. J Am Coll Cardiol. 2000;36(7):2154-2159.

54. Hillebrand U, Hausberg M, Stock C, et al. 17beta-estradiol increases volume, apical surface and elasticity of human endothelium mediated by $\mathrm{Na}+\mathrm{H}+$ exchange. Cardiovasc Res. 2006;69(4):916-924.

55. Smith NL, Blondon M, Wiggins KL, et al. Lower risk of cardiovascular events in postmenopausal women taking oral estradiol compared with oral conjugated equine estrogens. JAMA Intern Med. 2014;174(1):25-31.

56. Smith NL, Heckbert SR, Lemaitre RN, et al. Conjugated equine estrogen, esterified estrogen, prothrombotic variants, and the risk of venous thrombosis in postmenopausal women. Arterioscler Thromb Vasc Biol. 2006;26(12):2807-2812.

57. Simon JA, Bouchard C, Waldbaum A, Utian W, Zborowski J, Snabes MC. Low dose of transdermal estradiol gel for treatment of symptomatic postmenopausal women: a randomized controlled trial. Obstet Gynecol. 2007;109(3):588-596.

58. Bachmann GA, Schaefers M, Uddin A, Utian WH. Lowest effective transdermal 17beta-estradiol dose for relief of hot flushes in postmenopausal women: a randomized controlled trial. Obstet Gynecol. 2007;110(4):771-779.

59. Kicovic PM, Cortes-Prieto J, Milojević S, Haspels AA, Aljinovic A. The treatment of postmenopausal vaginal atrophy with Ovestin vaginal cream or suppositories: clinical, endocrinological and safety aspects. Maturitas. 1980;2(4):275-282.

60. Takahashi K, Manabe A, Okada M, Kurioka H, Kanasaki H, Miyazaki K. Efficacy and safety of oral estriol for managing postmenopausal symptoms. Maturitas. 2000;34(2):169-177. 


\section{Publish your work in this journal}

The International Journal of General Medicine is an international, A key focus is the elucidation of disease processes and management peer-reviewed open-access journal that focuses on general and internal medicine, pathogenesis, epidemiology, diagnosis, monitoring and treatment protocols. The journal is characterized by the rapid reporting of reviews, original research and clinical studies across all disease areas. protocols resulting in improved outcomes for the patient.The manuscript management system is completely online and includes a very quick and fair peer-review system. Visit http://www.dovepress.com/ testimonials.php to read real quotes from published authors.

Submit your manuscript here: http://www.dovepress.com/international-journal-of-general-medicine-journal 